\title{
Dry matter intake and feed efficiency profiles of 3 genotypes of Holstein-Friesian within pasture-based systems of milk production
}

\author{
J. Coleman, ${ }^{*} \dagger$ D. P. Berry, ${ }^{* 1}$ K. M. Pierce, † A. Brennan, ${ }^{*}$ and B. Horan ${ }^{*}$ \\ ${ }^{*}$ Teagasc, Moorepark Dairy Production Research Centre, Fermoy, Co. Cork, Ireland \\ †School of Agriculture, Food Science and Veterinary Medicine, University College Dublin, Belfield, Dublin 4, Ireland
}

\begin{abstract}
The primary objective of the study was to quantify the effect of genetic improvement using the Irish total merit index (Economic Breeding Index) on dry matter intake and feed efficiency across lactation and to quantify the variation in performance among alternative definitions of feed efficiency. Three genotypes of Holstein-Friesian dairy cattle were established from within the Moorepark dairy research herd: 1) low Economic Breeding Index North American Holstein-Friesian representative of the Irish national average dairy cow, 2) high genetic merit North American Holstein-Friesian, and 3) high genetic merit New Zealand Holstein-Friesian. Animals from within each genotype were randomly allocated to 1 of 2 possible intensive pasture-based feed systems: 1) the Moorepark pasture system (2.64 cows/ha and $500 \mathrm{~kg}$ of concentrate supplement per cow per lactation) and 2) a high output per hectare pasture system (2.85 cows/ha and 1,200 kg of concentrate supplement per cow per lactation). A total of 128 and 140 springcalving dairy cows were used during the years 2007 and 2008, respectively. Each group had an individual farmlet of 17 paddocks, and all groups were managed similarly throughout the study. The effects of genotype, feed system, and the interaction between genotype and feed system on dry matter intake, milk production, body weight, body condition score, and different definitions of feed efficiency were studied using mixed models with factorial arrangements of genotypes and feed systems accounting for the repeated cow records across years. No significant genotype-by-feed-system interactions were observed for any of the variables measured. Results showed that aggressive selection using the Irish Economic Breeding Index had no effect on dry matter intake across lactation when managed on intensive pasture-based systems of milk production, although the ranking of genotypes for feed efficiency differed depending on the definition of feed efficiency
\end{abstract}

Received September 1, 2009.

Accepted February 2, 2010.

${ }^{1}$ Corresponding author: donagh.berry@teagasc.ie used. Performance of animals grouped on alternative definitions of feed efficiency showed that conventional definitions such as feed conversion efficiency or residual feed intake may be inappropriate measures of efficiency for lactating dairy cows. An alternative definition, residual solids production, is proposed. This definition of feed efficiency identifies animals that produce greater volumes of milk solids at similar levels of feed intake without excessive body tissue mobilization and with improved fertility performance. The results also suggest that although there are differences in feed efficiency between strains of Holstein-Friesian, there is also variation within genotypes so that improvements in feed efficiency can be realized if the appropriate definition of feed efficiency is incorporated into breeding programs.

Key words: genotype, feed system, dry matter intake, feed efficiency

\section{INTRODUCTION}

An increasing world population and greater demand on agricultural land for nonagricultural crops will present many opportunities and challenges for dairy production systems into the future. The increased milk production required to meet future demands will be realized by expansion of dairy herds, as well as increased efficiency of milk production through improvements in management and genetic merit for feed efficiency (Dillon et al., 2008). Because feed costs account for approximately $80 \%$ of total variable costs of milk production (Shalloo et al., 2004), differences in converting feed into additional volumes of milk solids ( $\mathrm{kg}$ of fat and protein) are, and will continue to be, of considerable importance. Increased efficiency will be realized through the identification of germplasm and feeding systems that can deliver increased volumes of milk solids from similar levels of feed inputs without compromising animal health and fertility.

Feed efficiency is not a new concept, and although research into this area is increasing, there are a multitude of definitions of feed efficiency, among which the most appropriate definition for dairy production systems is still unclear (Berry, 2009). One of the more commonly used measures of feed efficiency in dairy production sys- 
tems is feed conversion efficiency (FCE; Brody, 1945), or gross feed efficiency. Feed conversion efficiency is intrinsically included in dairy cattle breeding programs in Ireland and New Zealand, where both breeding goals include a positive weighting on increased milk-solids production and a negative weighting on BW. However, FCE does not account for mobilization of body condition, and consequently, animals losing body condition to support milk production may appear more efficient, particularly if the evaluation is done in early lactation. Increased losses in body condition are associated with poor fertility performance (Roche et al., 2007) and health (Berry et al., 2007a), which could reduce the benefits of improved FCE.

Another measure of feed efficiency, termed net feed efficiency or residual feed intake (RFI; Koch et al., 1963), is defined as the difference between actual feed intake and feed intake predicted from animal performance. Energy requirements are calculated from energy tables (NRC, 2001) or by comparison among contemporaries within a sample population by regressing energy intake on the energy sinks. Selection for RFI in beef production systems seems logical because it identifies animals that consume less than expected for a given BW gain. However, in dairy production systems, increasing milk-solids production for a given level of input may be a more appropriate feed-efficiency measure provided health and fertility are not impaired, as pasture-based systems of milk production are often restricted by land area and, therefore, herbage supply.

Several studies have attempted to measure the effect of different breeds or strains of breeds on DMI and feed efficiency (Buckley et al., 2007; Lopez-Villalobos et al., 2008), but they have not reported DMI and feed efficiency across lactation. Buckley et al. (2007) reported that Holstein-Friesians (HF) of New Zealand origin were lighter, produced less milk solids, but had similar DMI to contemporaries of North American origin. Animals of New Zealand origin had greater (i.e., inferior) RFI but similar FCE to animals of North American origin. Within breeds, Lopez-Villalobos et al. (2008) demonstrated that differences in RFI between animals partitioned into high and low RFI were attributable to differences in total DMI.

Given the large number of measures of feed efficiency in the literature (Berry, 2009), it is unclear what the most appropriate definition(s) for use in future dairy breeding selection programs should be. There is also a lack of research into the effect of differences in various definitions of feed efficiency and their associations with health and fertility. The objective of this study was, therefore, to describe the DMI and feed efficiency of the various genotypes of HF across lactation when managed under 2 different intensive pasture-based systems and then to compare the utility of several definitions of feed efficiency in terms of associations with both productive and reproductive performance.

\section{MATERIALS AND METHODS}

The study formed part of a larger overall study designed to examine the biological and economic effect of genetic improvement across 2 intensive pasture-based feed systems. A more detailed description of the strains of HF, feed systems, and experimental design has been reported previously (Coleman et al., 2009). The study was carried out at Moorepark dairy research center in Ireland over a 2-yr period (2007 and 2008).

\section{Animals}

Three genotypes of HF dairy cattle were established for this study from within the Moorepark dairy research herd based on their origin and overall genetic merit as measured using the Irish total merit index (Economic Breeding Index, EBI; Berry et al., 2007b). A total of 265 lactations from 175 spring-calving dairy cows were studied, with 128 and 140 cows in years 1 and 2 , respectively (Table 1 ). The parity structure was $33 \%$ first lactation and $25 \%$ second lactation, with the remainder consisting of third lactation or greater. The genotypes compared were 1) indicative of the current Irish national average dairy cow of low genetic merit and of North American HF origin (LowNA), 2) high genetic potential North American HF (HighNA), and 3) high genetic potential New Zealand HF (HighNZ). The LowNA group was selected to represent the characteristics of the average genetic potential dairy cow on Irish dairy farms at the time of the study (Irish Cattle Breeding Statistics, 2006-2008; ICBF, 2008). These animals were used to quantify the intake capacity and feed efficiency of the average Irish dairy cow within intensive futuristic production systems. The LowNA animals were also used as the base group to quantify the effect of genetic improvement using the EBI on DMI and feed efficiency. The HighNA genotype was used to measure the effect of genetic improvement from using high EBI North American HF sires. The HighNZ group was used to compare the effects of genetic improvement through high EBI New Zealand HF ancestry compared with North American HF ancestry of equally high overall genetic potential. The HighNZ herd represents a HF that was selected within a seasonal pasture-based system similar to that in Ireland but with a greater emphasis on milk composition, compact seasonal-calving fertility targets, and reduced BW (which is an indirect method for genetic selection for increased FCE). The average percentage of North American Holstein genes in the 
Table 1. Number of cows within each genotype ${ }^{1}$ and feed system ${ }^{2}$ for each year of the study

\begin{tabular}{|c|c|c|c|c|c|c|}
\hline \multirow[b]{2}{*}{ Item } & \multicolumn{2}{|c|}{ LowNA } & \multicolumn{2}{|c|}{ HighNA } & \multicolumn{2}{|c|}{ HighNZ } \\
\hline & MK & $\mathrm{HC}$ & MK & $\mathrm{HC}$ & MK & $\mathrm{HC}$ \\
\hline \multicolumn{7}{|c|}{ No. of animals } \\
\hline Year 1 & 21 & 21 & 21 & 21 & 22 & 22 \\
\hline Year 2 & 23 & 23 & 23 & 23 & 24 & 24 \\
\hline \multicolumn{7}{|c|}{ No. of lactation records } \\
\hline Parity 1 & 15 & 16 & 16 & 17 & 16 & 15 \\
\hline Parity 2 & 11 & 9 & 12 & 9 & 10 & 12 \\
\hline Parity 3+ & 18 & 19 & 16 & 18 & 20 & 19 \\
\hline
\end{tabular}

${ }^{1}$ LowNA = Irish national average genetic merit North American Holstein-Friesian; HighNA = high genetic merit North American Holstein-Friesian; HighNZ = high genetic merit New Zealand Holstein-Friesian.

${ }^{2} \mathrm{MK}=$ Moorepark; $\mathrm{HC}=$ high output per hectare.

LowNA and HighNA animals was $90 \%$ in comparison with $12.5 \%$ for HighNZ animals.

\section{Feed Systems and Grazing Management}

All pluriparous animals were randomly allocated to 1 of 2 possible post-European Union-milk-quota pasturebased feed systems: 1) the Moorepark pasture (MK) system, a system designed as a low cost pasture management system for a post-European Union-milk-quota scenario based on high levels of pasture utilization and low levels of concentrate supplementation, and 2) a high output per hectare (HC) system, a system designed as a high productivity pasture management system to increase milk output per hectare. The MK system incorporates high grass allowance, high stocking rate (2.64 cows/ha), and low concentrate inputs $(500 \mathrm{~kg} / \mathrm{cow}$ per lactation), whereas the $\mathrm{HC}$ system maintains similar high levels of pasture utilization, incorporating higher stocking rates (2.85 cows/ha) and increased levels of concentrate supplementation $(1,200 \mathrm{~kg} / \mathrm{cow})$.

To maximize the proportion of grazed grass in the diet, cows were turned out to pasture immediately postpartum and grazed whenever weather conditions allowed, only returning indoors under severe weather conditions. A total of 300 and 295 grazing days were available in years 1 and 2, respectively. A separate farmlet of 17 paddocks was created for each of the 6 treatment groups so that all groups could be managed similarly, on a common rotation length, grazing similar pregrazing herbage masses and achieving similar levels of grass utilization ( $>4 \mathrm{~cm}$, Table 2 ). To account for the stocking-rate differential, paddock sizes for the HC feed system were $8 \%$ smaller than those for the MK feed system. Consequently, daily herbage allowance was $8 \%$ greater for the MK feed system compared with the HC feed system, and a differential of $3 \mathrm{~kg}$ of concentrate was maintained between the MK and $\mathrm{HC}$ feed system throughout the grazing season to ensure pasture utili- zation was similar for both feed systems. The ingredient composition of the concentrate feed was as follows: barley $25 \%$, corn gluten $26 \%$, beet pulp $35 \%$, soybean meal $11 \%$, and minerals plus vitamins 3\%. Grazing management was accomplished by weekly monitoring of farm grass cover. Paddock grass cover was monitored according to O'Donovan (1997) by harvesting a representative area $(0.5 \mathrm{~m} \times 0.5 \mathrm{~m})$ to $4 \mathrm{~cm}$, weighing the sample, determining DM content, and calculating DM yield. High pasture quality was maintained by removal of surplus grass throughout the experiment as silage (O'Donovan, 2000). Residency times were determined by maintaining a target postgrazing residual sward height of $5 \mathrm{~cm}$ in year 1 and $4 \mathrm{~cm}$ in year 2 .

\section{Animal Measurements}

Cows were milked twice daily throughout lactation across both years of the study. Milking took place at 0700 and $1530 \mathrm{~h}$ daily. Weekly milk production was derived from individual cow milk yield $(\mathrm{kg})$ recorded at each milking (Dairymaster, Causeway, Co. Kerry, Ireland). Milk fat, protein, and lactose concentrations were determined in successive pm and am samples of milk each week using Milkoscan 203 (Foss Electric DK-3400, Hillerod, Denmark), and weekly fat, protein, lactose, and milk-solids yields were calculated. Individual animal BW was recorded weekly upon exit from the milking parlor using an electronic scale (Tru-Test Limited, Auckland, New Zealand) calibrated weekly against known weights. Animal BCS was measured every 3 wk throughout the study on a 0 to 5 scale $(0$ $=$ thin, 5 = fat) in increments of 0.25 as outlined by Edmonson et al. (1989). Body condition was assigned by one individual throughout the study.

Measurements of individual cow DMI were estimated using the n-alkane technique (Mayes et al., 1986) as modified by Dillon and Stakelum (1989). Individual DM intakes were measured on 6 occasions during the 
Table 2. Dietary allocations for the 2 feed systems averaged over the 6 measurement periods

\begin{tabular}{|c|c|c|c|c|}
\hline \multirow[b]{2}{*}{ Item } & \multicolumn{2}{|c|}{ Feed system $^{1}$} & \multirow[b]{2}{*}{$\mathrm{SE}^{2}$} & \multirow[b]{2}{*}{$P$-value } \\
\hline & MK & $\mathrm{HC}$ & & \\
\hline Grass preheight $(\mathrm{cm})$ & 10.6 & 10.7 & 0.74 & 0.57 \\
\hline Grass postheight $(\mathrm{cm})$ & 4.3 & 4.2 & 0.28 & 0.39 \\
\hline Pregrazing mass $^{3}$ (kg of DM/ha) & 1,857 & 1,620 & 163.3 & 0.57 \\
\hline Daily grass allowance ( $\mathrm{kg}$ of $\mathrm{DM} / \mathrm{cow})$ & 14.5 & 13.6 & 0.82 & 0.10 \\
\hline Daily concentrate allowance ( $\mathrm{kg}$ of DM/cow) & 0.35 & 2.93 & 0.328 & $<0.001$ \\
\hline
\end{tabular}

grazing season in 2007 and again in 2008 corresponding with the first rotation in early lactation and every 30 to $40 \mathrm{~d}$ subsequently (Table 3 ). Observations of DMI across animals ranged from 16 to 288 DIM. Cows were dosed twice daily after milking with paper bungs containing $500 \mathrm{mg}$ of C32-alkane (n-dotriacontane) over a 12-d period. On d 7 to 12, fecal grab samples from each cow were collected. These were subsequently bulked and subsampled for analysis. Selected herbage samples were also taken to grazing height following close observation of the grazing of the cows. The ratio of herbage C33alkane (tritriacontane) to dosed C32-alkane was used to estimate DMI.

\section{Pasture Measurements}

During each measurement period, pregrazing herbage mass ( $>4$-cm horizon) was determined before grazing in each paddock for each genotype and feed system based on 2 strips ( $0.70 \mathrm{~m}$ wide, $7 \mathrm{~m}$ long) of grass cut with an Agria mower (Agria-Werke GmbH, Mockmuhl/Wurtt, Germany). The herbage from each strip was weighed, and a subsample was taken and dried for $16 \mathrm{~h}$ at $95^{\circ} \mathrm{C}$ for DM determination. Ten grass-height measurements were recorded before and after harvesting on each cut strip using an electronic plate meter with a plastic plate $(30 \times 30 \mathrm{~cm}$ and $4.5 \mathrm{~kg} / \mathrm{m}$; Agrosystèmes, Choiselle,
France). Based on these measurements, it was possible to measure sward density:

$$
\begin{aligned}
& \text { sward density }(\mathrm{kg} \text { of } \mathrm{DM} / \mathrm{cm} \text { per ha) }= \\
& \text { herbage mass }(\mathrm{kg} \text { of } \mathrm{DM} / \mathrm{ha}) /[\text { precutting } \\
& \text { height }(\mathrm{cm})-\text { postcutting height }(\mathrm{cm})]
\end{aligned}
$$

A further 30 sward heights were taken before grazing, and 30 heights were taken after grazing. These sward heights, in combination with sward density, were used to calculate average paddock pregrazing herbage mass:

pregrazing herbage mass $(\mathrm{kg}$ of $\mathrm{DM} / \mathrm{ha})=$ [pregrazing sward height $(\mathrm{mm})$ - postgrazing residual sward height $(\mathrm{mm})] \times$ sward density.

Daily herbage allowance (DHA) and group average grass DMI could then be calculated based on pregrazing herbage mass and residency period within that paddock area:

DHA $(\mathrm{kg}$ of $\mathrm{DM} /$ cow per $\mathrm{d})=$ pregrazing herbage mass $(>4 \mathrm{~cm})(\mathrm{kg}$ of $\mathrm{DM}) \times$ paddock area $($ ha $) /$ number of cows in group/days grazing.

\begin{tabular}{|c|c|c|c|c|c|c|c|c|c|}
\hline Period & Date & \multicolumn{3}{|c|}{ Genotype $^{1}$} & \multicolumn{2}{|c|}{ Feed system $^{2}$} & \multicolumn{3}{|c|}{ Parity } \\
\hline 2 & April 30 & $83(76)$ & $84(78)$ & $90(84)$ & $130(79)$ & $127(79)$ & $90(91)$ & $61(78)$ & $106(70)$ \\
\hline 3 & June 9 & 87 (111) & $84(117)$ & $91(122)$ & $133(116)$ & 129 (117) & $89(129)$ & $63(115)$ & $110(106)$ \\
\hline 4 & July 26 & $88(160)$ & $85(165)$ & $91(170)$ & $133(165)$ & $131(166)$ & $91(179)$ & $63(164)$ & $110(154)$ \\
\hline 5 & September 11 & 88 (206) & $85(211)$ & $91(216)$ & $133(211)$ & $130(211)$ & $90(224)$ & $63(210)$ & $110(200)$ \\
\hline
\end{tabular}

Table 3. Number of intake records within each genotype, feed system, and parity for each measurement period throughout the study (mean DIM in parentheses)

${ }^{1}$ LowNA = Irish national average genetic merit North American Holstein-Friesian; HighNA = high genetic merit North American HolsteinFriesian; HighNZ = high genetic merit New Zealand Holstein-Friesian.

${ }^{2} \mathrm{MK}=$ Moorepark pasture; $\mathrm{HC}=$ high concentrate. 
Postgrazing sward measurements were also used as an ongoing verification tool to ensure target postgrazing residual sward heights were being maintained for each genotype and feed system so grazing severity and grass utilization were equal for all groups. A further composite sample was collected for each genotype. This sample was dried for $48 \mathrm{~h}$ at $40^{\circ} \mathrm{C}$, milled through a 1-mm sieve, and analyzed for chemical composition.

\section{Data Editing and Definition of Performance Variables}

Lactation curves for milk, milk-solids, fat, protein, and lactose yield and BW were described by the Wilmink exponential function (Wilmink, 1987) using Proc NLIN (SAS Institute, 2006); daily data for BCS were described using ASREML (Gilmour et al., 2009) and have been reported previously (Coleman et al., 2010). A smoothing spline with 6 knots at d 40, 80, 120, 160, 200, and 240 was also fitted to data for total DMI and grass DMI separately for each cow using ASREML (Gilmour et al., 2009). Daily data for total and grass DMI were obtained from the fitted curves. Daily change in $\mathrm{BW}(\Delta \mathrm{BW})$ was calculated for each animal as the first derivative of the lactation profile for BW.

Feed efficiency variables were defined for each DIM using the daily estimates for the components of each feed-efficiency measure. Because of a lack of data on intake measurements before d 16 and after 288 DIM, feed efficiency variables were only defined between 21 and 288 DIM. The 5 definitions of feed efficiency used were

1) FCE, defined as

$\mathrm{kg}$ of milk solids/kg of total DMI

2) Milk solids per kilogram of BW, defined as

$\mathrm{kg}$ of milk solids/kg of BW

3) Total DMI per kilogram of BW, defined as total $\mathrm{DMI} / \mathrm{kg}$ of $\mathrm{BW}$

4) RFI, defined as

$$
\begin{aligned}
& \mathrm{RFI}_{\mathrm{t}}=\text { total DMI }-\left(\text { year }_{\mathrm{y}}+\text { fat yield }_{\mathrm{t}}+\right.\text { protein } \\
& \text { yield }_{\mathrm{t}}+\text { lactose yield } \\
& \left.\mathrm{t}+\mathrm{BW}_{\mathrm{t}}^{0.75}+\Delta \mathrm{BW}_{\mathrm{t}}+\mathrm{BCS}_{\mathrm{t}}\right)
\end{aligned}
$$

5) Residual solids production (RSP), defined as

$$
\begin{aligned}
\mathrm{RSP}_{\mathrm{t}}= & \text { milk solids yield } \\
& -\left(\text { year }_{\mathrm{y}}+\text { total } \mathrm{DMI}_{\mathrm{t}}\right. \\
& \left.+\mathrm{BW}_{\mathrm{t}}^{0.75}+\Delta \mathrm{BW}_{\mathrm{t}}+\mathrm{BCS}_{\mathrm{t}}\right)
\end{aligned}
$$

For both RFI and RSP, $\mathrm{t}=$ day in milk, $\mathrm{y}=$ year $(1$ or 2), $\Delta \mathrm{BW}=$ instantaneous change in $\mathrm{BW}$ at day $\mathrm{t}$.

Number of days pregnant was not associated with DMI and milk-solids production and was, therefore, omitted from the model to calculate RFI and RSP. At 288 DIM, cows that were identified as pregnant were, on average, $192 \mathrm{~d}$ pregnant. The energy generated from a 1-kg loss in BW is less than the energy required for a 1-kg gain in BW (O'Mara, 2000). To account for this, piecewise regression, with a breakpoint at zero BW change, was used to quantify the association between total DMI and BW change for the estimation of RFI and between milk solids and BW change for the estimation of RSP. The possible existence of multicollinearity among the independent variables in the models to predict RFI and RSP was investigated on each DIM, but it did not exist. Nonlinear associations between dependent and independent variables for each DIM were tested both graphically and statistically based on the significance of the quadratic regression coefficient. After accounting for the multiple testing, there were no nonlinear associations.

To characterize the performance of animals differing in feed efficiency, the average RFI, RSP, and FCE of all animals from 21 to 60 DIM and from 21 to 288 DIM were quantified within strata of genotype, feed system, parity, and month of calving. Parity was coded as lactation 1,2 , and 3 or greater, and month of calving was grouped as January, February, and March or later. Animals within each stratum were then assigned into low, medium, and high efficiency categories as determined by the respective efficiency value. When the number of animals in each stratum was not a multiple of 3 , excess animals in the middle strata were discarded at random. This was done to ensure a balanced structure within each stratum. From the 265 original lactation records, 213 lactations were retained and allocated between groups for RFI, RSP, and FCE separately.

\section{Statistical Analysis}

The effects of feed system on daily feed allocations across each measurement period and the effect of genotype on pasture quality across measurement periods were determined using PROC MIXED (SAS Institute, 2006). Year was included as a repeated effect; a compound symmetry covariance structure among records provided the best fit to the data. Fixed effects tested for inclusion in the models were genotype, feed system, year, week of year, and their interactions. Nonsignificant effects $(P>0.05)$ were removed from the model by backward elimination.

The effect of genotype and feed system on mean daily milk production, grass DMI, total DMI, and feed ef- 
ficiency across lactation was determined using PROC MIXED (SAS Institute, 2006) in which the week of lactation effect was included as a repeated effect with a first-order autoregressive covariance structure with homogenous variances assumed among records within cow-year. Initial models included the effects of genotype, feed system, year, parity, week of lactation, and their interactions. Nonsignificant effects $(P>0.05)$ were removed from the model by backward elimination.

The association between animals with low, medium, and high RFI, FCE, and RSP (as defined previously) and daily production, grass DMI, total DMI, BW, BCS, and other feed-efficiency variables measured at weekly intervals between 21 to 60 DIM and between 21 to 288 DIM was determined using PROC MIXED (SAS Institute, 2006). Week of lactation effect was included as a repeated effect within cow and a first-order autoregressive covariance structure with homogenous variances fitted among records within cow-year. Fixed effects included in the models were RFI, FCE, or RSP group; DIM; and their interactions. Nonsignificant effects $(P$ $>0.05$ ) were removed from the model by backward elimination.

The association between RFI and RSP groups and the fertility-interval traits (i.e., mean calving date, calvingto-service interval, calving-to-conception interval, and calving interval) were determined using PROC MIXED (SAS Institute, 2006). Year was included as a repeated effect within cow and a compound symmetry covariance structure fitted among records within cow-year.

The association between animals with low, medium, and high FCE, RFI, and RSP between 21 to 60 DIM and between 21 to 288 DIM and the binary fertility traits (i.e., pregnancy rate to first and second service, 42-d pregnancy rate, submission rate, embryo mortality, and overall pregnancy rates) was determined using generalized estimated equations (GEE; PROC GENMOD, SAS Institute, 2006); a logit link function was used, and a binomial distribution of the data was assumed. Cow was included as a repeated effect. Odds ratios were calculated as the exponent of the model solutions. In all cases, the low FCE, RFI, and RSP groups were used as the reference groups.

The association between animals with low, medium, and high FCE, RFI, and RSP and survival was determined using survival analysis (PROC TPHREG, SAS Institute, 2006); survival was expressed as the relative hazard of a cow being culled at day $t$, given that it had not been culled at day $\mathrm{t}-1$ in the exposed group relative to the reference group. The low FCE, RFI, and RSP groups were used as the reference groups.

\section{RESULTS}

\section{The Effects of Genotype and Feed System on Pasture Allowance and Quality}

The effects of feed system on herbage and concentrate allocations across all of the measurement periods are described in Table 2. Both feed systems were managed throughout the study so that cows grazed swards of similar pregrazing yield and sward height to similar postgrazing residual sward height. Due to the difference in stocking rates, the MK feed system received an allocation of $8 \%$ greater daily grass allowance than the $\mathrm{HC}$ feed system. Animals on the $\mathrm{HC}$ feed system were fed $2.78 \mathrm{~kg}$ of concentrate per day to compensate for the reduced grass allowance.

Grazing management rules were applied equally across all groups, and consequently, grass quality did not differ between groups (Table 4). All cows were fed the same concentrates and silage, and therefore, quality did not differ between genotypes. Mean concentrate quality was $157 \mathrm{~g} / \mathrm{kg}$ of CP, $270 \mathrm{~g} / \mathrm{kg}$ of NDF, $80.9 \mathrm{~g} /$ $\mathrm{kg}$ of crude fiber, and $96.2 \mathrm{~g} / \mathrm{kg}$ of ash. Mean silage quality was $151 \mathrm{~g} / \mathrm{kg}$ of CP, $553 \mathrm{~g} / \mathrm{kg}$ of NDF, $378 \mathrm{~g} / \mathrm{kg}$ of $\mathrm{ADF}$, and $94 \mathrm{~g} / \mathrm{kg}$ of ash.

\section{The Effects of Genotype and Feed System on Intake and Feed Efficiency}

The effects of genotype and feed system on total DMI and feed efficiency are described in Table 5 and Figure 1. There were no interactions between genotype and feed system observed for any of the variables investigated. Animals on the MK feed system were on the lower stocking rate and, consequently, had greater grass DMI across lactation compared with the HC feed system. Due to increased concentrate supplementation, animals in the HC feed system had greater total DMI across lactation compared with animals on the MK feed system. The effect of genotype on grass DMI or total DMI did not differ $(P>0.05)$ across different stages of lactation (Figure 1), but there was a difference $(P<$ 0.001) in total DMI between feed systems across lactation, with the greatest differences in total DMI between feed systems occurring from approximately 105 to 231 DIM (Figure 1).

From 21 to 288 DIM (Table 5), milk or milk-solids yield per day did not differ between genotypes. From 21 to 288 DIM, HighNZ animals were approximately $30 \mathrm{~kg}$ lighter compared with their HighNA and LowNA counterparts, with HighNZ animals having the great- 
Table 4. Measurements of pasture quality $(\mathrm{g} / \mathrm{kg}$ of $\mathrm{DM})$ for each genotype averaged across the 6 measurement periods

\begin{tabular}{|c|c|c|c|c|c|}
\hline \multirow[b]{2}{*}{ Item } & \multicolumn{3}{|c|}{ Genotype $^{1}$} & \multirow[b]{2}{*}{$\mathrm{SE}^{2}$} & \multirow[b]{2}{*}{$P$-value } \\
\hline & LowNA & HighNA & HighNZ & & \\
\hline OM digestibility & 843 & 839 & 841 & 1.8 & 0.32 \\
\hline $\mathrm{CP}$ & 205 & 206 & 205 & 4.1 & 0.95 \\
\hline NDF & 422 & 425 & 421 & 2.9 & 0.61 \\
\hline $\mathrm{ADF}$ & 265 & 264 & 265 & 1.9 & 0.84 \\
\hline Ash & 80 & 79 & 79 & 0.9 & 0.88 \\
\hline
\end{tabular}

${ }^{1}$ LowNA = Irish national average genetic merit North American Holstein-Friesian; HighNA = high genetic merit North American Holstein-Friesian; HighNZ = high genetic merit New Zealand Holstein-Friesian.

${ }^{2} \mathrm{SE}=$ pooled standard error.

est BCS compared with LowNA animals and HighNA animals being intermediate.

Across lactation, milk yield, fat yield, protein yield, lactose yield, BW, BW change, and BCS explained between 75 and $87 \%$ of the daily variation in DMI for each cow; the median was $86 \%$. The mean coefficient of variation of total DMI across lactation was 0.15 . The multiple coefficient of determination for the model to estimate daily RSP varied from 0.51 to 0.80 with a median of 0.77 ; the mean coefficient of variation for milk-solids production across lactation was 0.18 . The correlation, within week of lactation, between RFI and RSP was -0.68. A total of 90 animals had measures in 2 consecutive lactations. The repeatability across lactations for FCE, RFI, and RSP was $0.42,0.28$, and 0.33 , respectively.

The ranking of genotypes for feed efficiency was not consistent across the different definitions of feed efficiency used. From 21 to 288 DIM, HighNZ and HighNA animals had the best (i.e., highest) FCE and RSP com- pared with LowNA animals (Table 5). The HighNA animals had the best (i.e., lowest) RFI compared with HighNZ and LowNA animals. HighNZ animals produced the greatest amount of milk solids per kilogram of BW and had the greatest total DMI per kilogram of BW compared with HighNA and LowNA animals. The effects of genotype on daily RFI and RSP across lactation (21 to 288 DIM) are described in Figures 2 and 3 . The effect of genotype on RFI differed across lactation, with HighNA animals having the lowest RFI. The LowNA animals began lactation with low RFI, which increased to mid lactation, whereas HighNZ animals began lactation with high RFI, which declined toward mid lactation. The effect of genotype on RSP across lactation did not differ $(P>0.05)$ by DIM.

Between 21 to 288 DIM, animals on the MK feed system consumed $1.0 \mathrm{~kg} / \mathrm{d}$ more grass DMI than animals on the $\mathrm{HC}$ feed system (Table 5). Because of differences in concentrate supplementation, animals in the $\mathrm{HC}$ feed system consumed $1.3 \mathrm{~kg}$ of total DMI per day more and

Table 5. The effect of genotype ${ }^{1}$ and feeding system ${ }^{2}$ on milk production, feed intake, and feed efficiency of spring-calving dairy cows between 21 and 288 DIM

\begin{tabular}{|c|c|c|c|c|c|c|c|c|c|c|}
\hline Item & \multicolumn{2}{|c|}{ LowNA } & \multicolumn{2}{|c|}{ HighNA } & \multicolumn{2}{|c|}{ HighNZ } & $\mathrm{SE}^{3}$ & \multicolumn{3}{|c|}{$P$-value ${ }^{4}$} \\
\hline Milk yield $(\mathrm{kg} / \mathrm{d})$ & 18.3 & 20.6 & 18.9 & 20.6 & 18.5 & 19.6 & 0.59 & 0.60 & $<0.001$ & 0.75 \\
\hline Grass DMI (kg/d) & 15.7 & 14.6 & 15.6 & 14.5 & 15.3 & 14.5 & 0.22 & 0.49 & $<0.001$ & 0.66 \\
\hline Total DMI (kg/d) & 16.3 & 16.9 & 16.2 & 16.8 & 16.0 & 16.9 & 0.24 & 0.84 & $<0.001$ & 0.72 \\
\hline BW (kg) & 531 & 532 & 539 & 541 & 497 & 513 & 7.1 & $<0.001$ & 0.016 & 0.51 \\
\hline Residual feed intake (kg of DM/d) & 0.00 & 0.26 & -0.35 & -0.12 & -0.01 & 0.40 & 0.132 & 0.002 & 0.004 & 0.72 \\
\hline Residual solids production (g/d) & -73 & -8 & -7 & 46 & 9 & 17 & 25.7 & 0.04 & 0.05 & 0.49 \\
\hline Milk solids $/ \mathrm{kg}$ of $\mathrm{BW}(\mathrm{g} / \mathrm{kg})$ & 2.6 & 2.9 & 2.6 & 2.9 & 2.9 & 3.1 & 0.06 & $<0.001$ & $<0.001$ & 0.93 \\
\hline Total DMI/kg of BW $(\mathrm{g} / \mathrm{kg})$ & 30.4 & 32.4 & 29.9 & 31.8 & 31.7 & 33.7 & 0.42 & $<0.001$ & $<0.001$ & 0.98 \\
\hline
\end{tabular}

${ }^{1}$ LowNA = Irish national average genetic merit North American Holstein-Friesian; HighNA = high genetic merit North American HolsteinFriesian; HighNZ = high genetic merit New Zealand Holstein-Friesian.

${ }^{2} \mathrm{MK}=$ Moorepark; HC $=$ high output per hectare.

${ }^{3} \mathrm{SE}=$ pooled standard error.

${ }^{4} \mathrm{G}=$ genotype; $\mathrm{FS}=$ feeding system. 
(a)
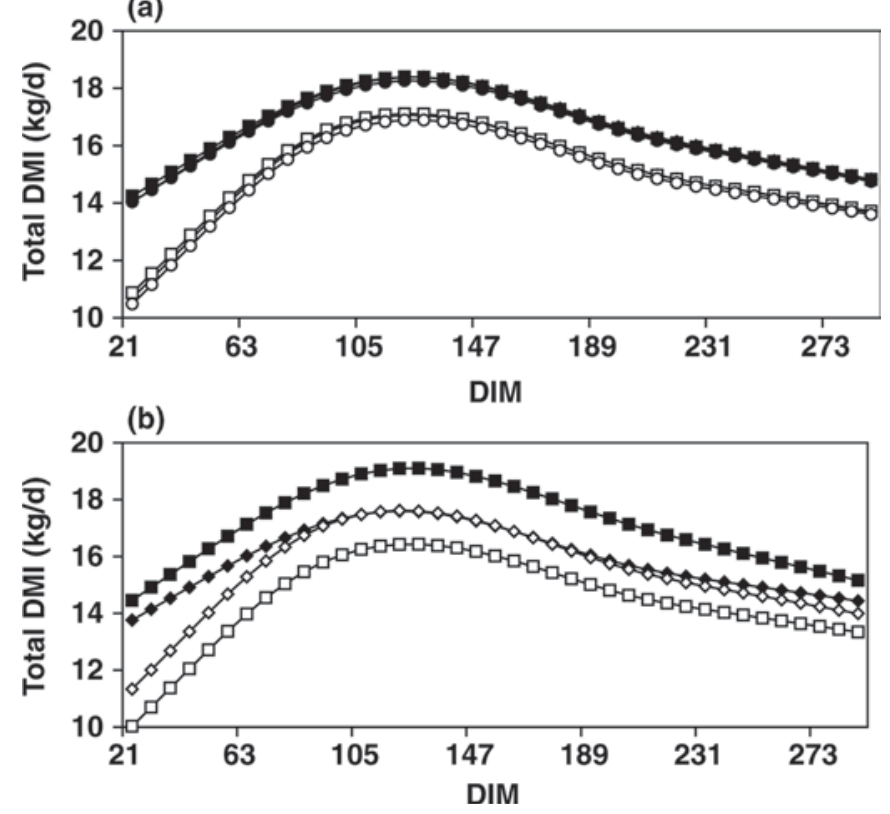

Figure 1. The effects of (a) genotype (HighNA $\bullet, \diamond$; LowNA $\boldsymbol{\square}$ $\square$; and HighNZ $\bullet, \bigcirc$ ) and (b) feed system (Moorepark $\bullet, \diamond$; and high concentrate $\mathbf{\square}, \square$ ) on total (solid symbols) and grass (open symbols) DMI across lactation. HighNA = high genetic merit North American Holstein-Friesian; LowNA = Irish national average genetic merit North American Holstein-Friesian; HighNZ = high genetic merit New Zealand Holstein-Friesian.

produced an additional $2.2 \mathrm{~kg}$ of milk and $0.15 \mathrm{~kg}$ of milk solids per day compared with animals on the MK feed system. There were no differences in BW between feed systems across lactation, although animals on the HC feed system were 0.06 BCS units greater $(P<0.05)$ than animals on the MK feed system.

The effect of feed system on feed efficiency was also not consistent across the alternative definitions. Animals on the HC feed system had, on average, a higher (i.e., worse) RFI (0.16 kg of DMI/d) compared with animals on the MK feed system $(-0.14 \mathrm{~kg}$ of DMI/d). Animals on the HC feed system had, on average, a higher (i.e., better) RSP (0.018 kg of milk solids/d) compared with animals on the MK feed system $(-0.022 \mathrm{~kg}$ of milk solids/d). Animals on the HC feed system had greater milk-solids production per kilogram of $\mathrm{BW}$ and total DMI per kilogram of BW (2.9 and $33 \mathrm{~g} / \mathrm{d}$, respectively) compared with the animals on the MK feed system (2.7 and $31 \mathrm{~g} / \mathrm{d}$, respectively). The effects of feed system on RFI and RSP from 21 to 288 DIM are illustrated in Figures 2 and 3. The effect of feed system on RFI differed $(P<0.001)$ by DIM, with large differences in RFI occurring between feed systems in early lactation and declining toward mid lactation. The effect of feed system on RSP also differed $(P<0.001)$ by DIM, with the 2 feed systems diverging after approximately 105 DIM.

\section{Characteristics of Animals Partitioned on RFI, RSP, and FCE}

Mean daily milk production, grass DMI, total DMI, and feed efficiency of animals differing in average FCE, RFI, and RSP from 21 to 288 DIM are described in Table 6. Increased FCE was associated with increased milk yield and milk-solids production, lower total DMI, and decreased BCS. Increased FCE was also associated with lower RFI, increased RSP, and increased milksolids production per kilogram of BW.

Milk-solids yield, BW, and BCS did not differ between animals in different RFI groups, but lower RFI (i.e., more efficient) animals consumed less feed. Decreased RFI was associated with increased RSP and FCE and decreased total and grass DMI per kilogram of BW, whereas there was no difference in milk-solids production per kilogram of BW.

There was no association between RSP and total or grass DMI, BW, or BCS, but animals with higher RSP (i.e., efficient animals) produced greater milk and milksolids yields. Increased RSP was associated with lower RFI and increased FCE and milk-solids production per kilogram of BW, with no difference in DMI per kilogram of BW among animals differing in RSP.

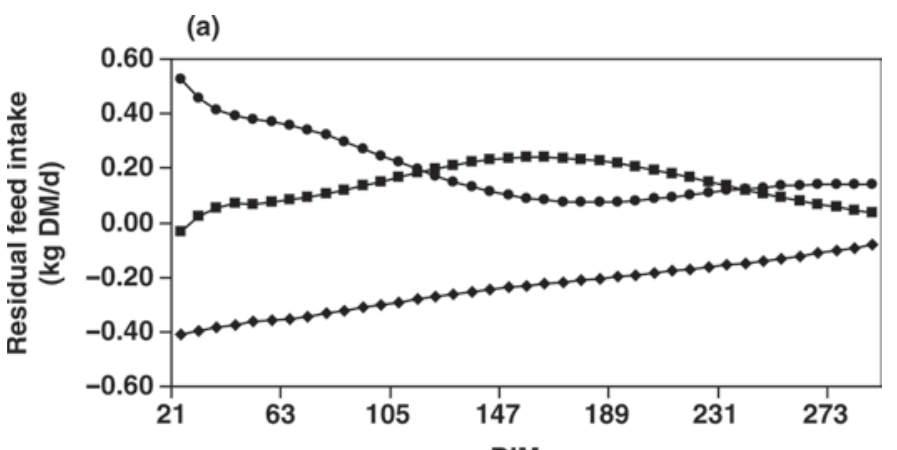

(b)

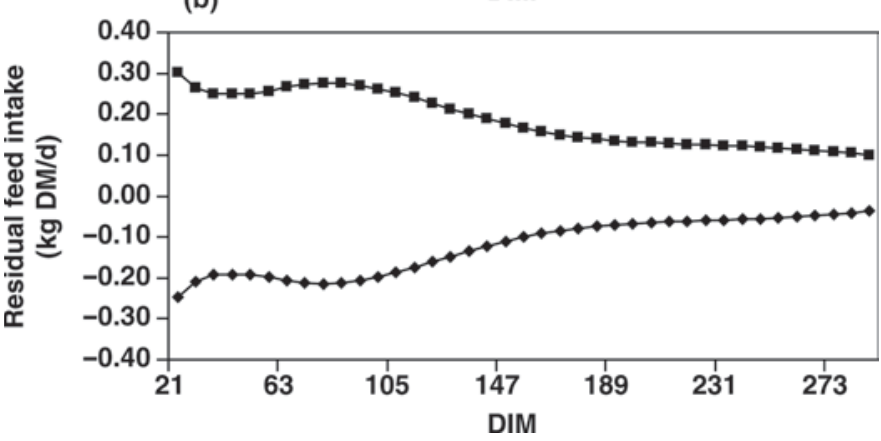

Figure 2. The effects of (a) genotype (HighNA $\bullet$, LowNA $\mathbf{\square}$, and HighNZ $\bullet$ ) and (b) feed system (Moorepark $\bullet$, and high concentrate 口) on residual feed intake across lactation. HighNA = high genetic merit North American Holstein-Friesian; LowNA = Irish national average genetic merit North American Holstein-Friesian; HighNZ = high genetic merit New Zealand Holstein-Friesian. 
Mean BW and BCS across lactation was not different $(P>0.05)$ between animals differing in average RFI or RSP between 21 and 288 DIM. Similarly, there were no differences in BW among animals differing in FCE. Animals of higher FCE had lower $(P<0.01)$ minimum $\mathrm{BCS}$ and lower BCS at the end of lactation (2.66 and 2.83 BCS units, respectively) compared with low FCE animals (2.79 and 2.95 BCS units, respectively).

The association between animals grouped on average FCE, RFI, and RSP between 21 and 60 DIM and between 21 and 288 DIM and fertility performance is described in Tables 7 and 8, respectively. Across both years of the study, mean calving date was the 20th of February, and the mean calving-to-service interval was $73 \mathrm{~d}$. There was no association between either FCE or RFI and any of the fertility measures recorded irrespective of whether FCE or RFI was based on performance in early lactation (21 to 60 DIM, Table 7 ) or over the whole of lactation (21 to 288 DIM, Table 8). Animals with high RSP in early lactation (i.e., between 21 and 60 DIM $)$ had a greater $(P<0.05)$ pregnancy rate after $42 \mathrm{~d}$ of the breeding season (66\% pregnant) compared with low RSP animals (44\% pregnant), resulting in greater $(P<0.01)$ overall pregnancy rates $(87 \%$ pregnant) among high RSP animals compared with low RSP animals (65\% pregnant). There was no association between RSP measured over the whole of lactation (21 to 288 DIM) and fertility performance (Table 8 ).

The association between animals grouped on average milk-solids production per kilogram of $\mathrm{BW}$ and total DMI per kilogram of BW between 21 and 288 DIM and milk production, grass DMI and total DMI, feed efficiency, BW, BCS, and fertility performance was investigated, but results are not presented. Animals with increased milk-solids production per kilogram of BW had greater $(P<0.05)$ milk-solids production, total DMI, FCE, RSP, and DMI per kilogram of BW compared with animals with lower milk-solids production per kilogram of BW, but there was no association $(P$ $>0.05$ ) with RFI, BW, BCS, or fertility performance. Animals with increased total DMI per kilogram of BW had greater $(P<0.05)$ milk-solids production, total DMI, milk-solids production per kilogram of BW, lighter BW, and poorer RFI and FCE compared with animals with lower total DMI per kilogram of BW but were not associated with RSP, total DMI per kilogram of $\mathrm{BW}, \mathrm{BCS}$, or fertility performance.

\section{DISCUSSION}

Traditionally, increased herd milk production has been achieved through increased stocking rates or increased milk production potential per cow (Dillon et al., 1995). In the future, volatile milk prices will inten-
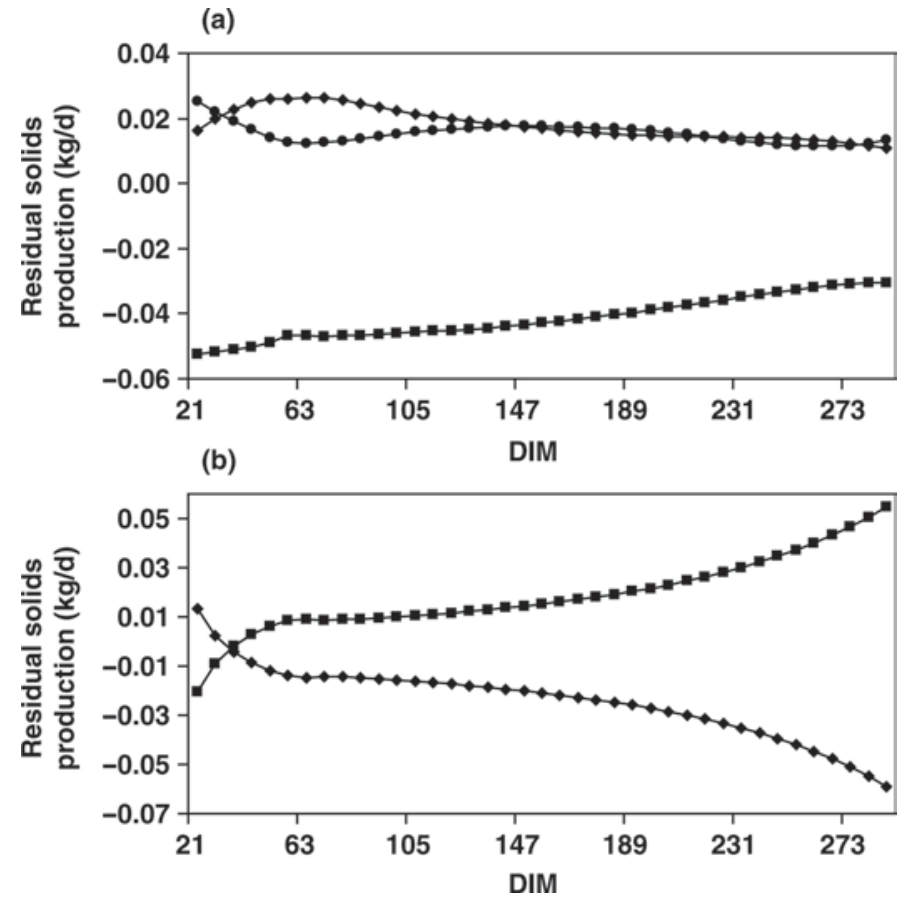

Figure 3. The effects of (a) genotype (HighNA $\bullet$, LowNA $\mathbf{\square}$, and HighNZ $\bullet$ ) and (b) feed system (Moorepark $\bullet$, and high concentrate -) on residual solids production across lactation. HighNA = high genetic merit North American Holstein-Friesian; LowNA = Irish national average genetic merit North American Holstein-Friesian; HighNZ = high genetic merit New Zealand Holstein-Friesian.

sify the price-cost squeeze placed on producers and will require the modification of pasture-based systems to reduce costs and maximize profit (Dillon et al., 2008). With feed costs accounting for the majority of the variable costs of production, grazed herbage can supply nutrients to dairy cows at a lower cost than supplemented feeds (Shalloo et al., 2004). To maximize the efficiency of intensive pasture-based systems of milk production, a comprehensive understanding of DMI requirements across lactation is required to aid grass-budgeting strategies to minimize dependence on high cost external feed sources. The objective of this study was, therefore, to measure the DMI of the various genotypes of HF across lactation when managed under 2 different intensive pasture-based systems and then to compare the efficacy of several definitions of feed efficiency in terms of both productive and reproductive potential.

\section{Defining Feed Efficiency Within Grass-Based Systems}

The most appropriate definition of feed efficiency in a dairy production system, especially within grazing systems, is not obvious. Whichever the definition of efficiency chosen, it must be relatively easy to measure, 
be under genetic control, and not be correlated with impaired health or fertility (Berry, 2009). Ratio traits such as FCE are beneficial because they are relatively easy to quantify, but by definition, they are correlated with their component traits and expected responses to selection are difficult to predict (Berry, 2009).

Feed efficiency based on residual from regression models may be more appropriate than those derived as ratios because by definition, if regression coefficients are estimated from the sample population, the residuals are independent of the energy sinks included in the regression model. However, predictive models need to include accurate measures of the independent and dependent variables as well as appropriate modeling of the regressor variables to accurately quantify the efficiency of an animal.

Traditionally, RFI models in beef production systems include (metabolic) BW at the midpoint of the study (Archer et al., 1997) or in dairy production systems, the average change in BW between 2 measurement periods (Buckley et al., 2007). However, in dairy production systems, BW change across lactation is characterized by a sharp decline at the start of lactation, followed by a steady increase thereafter (Roche et al., 2007). Therefore, more accurate methods of accounting for BW changes across lactation are required. Furthermore, because energy gained from tissue mobilization is less than energy required for BW gain (O'Mara, 2000), it is necessary to clearly differentiate between these phenomena. Piecewise regression allows for 2 separate regression models to be created with a breakpoint either chosen by an algorithm or explicitly chosen; in the present study, the breakpoint was set at zero (i.e., no BW change). This, therefore, facilitates the estimation of separate regression coefficients for BW gain and $\mathrm{BW}$ loss.

Furthermore, differences also occur in the composition of BW gain whereby there is a greater energy requirement for fat deposition compared with protein or water, although protein requires more energy to maintain (DiCostanzo et al., 1990). As a consequence of their respective breeding programs, animals of North American origin were of a lower BCS than animals of New Zealand origin (Coleman et al., 2010). Therefore, in the present study, BCS was included within the multiple regression models to account for differences in body composition.

Previous methods of calculating RFI traditionally include SCM production as a regressor (Buckley et al., 2007) to represent the energy requirements for milk production. This does not imply independence of RFI from the individual milk components such as milk, fat, protein, and lactose yields. To overcome this, DMI in the present study was regressed on protein, fat, and

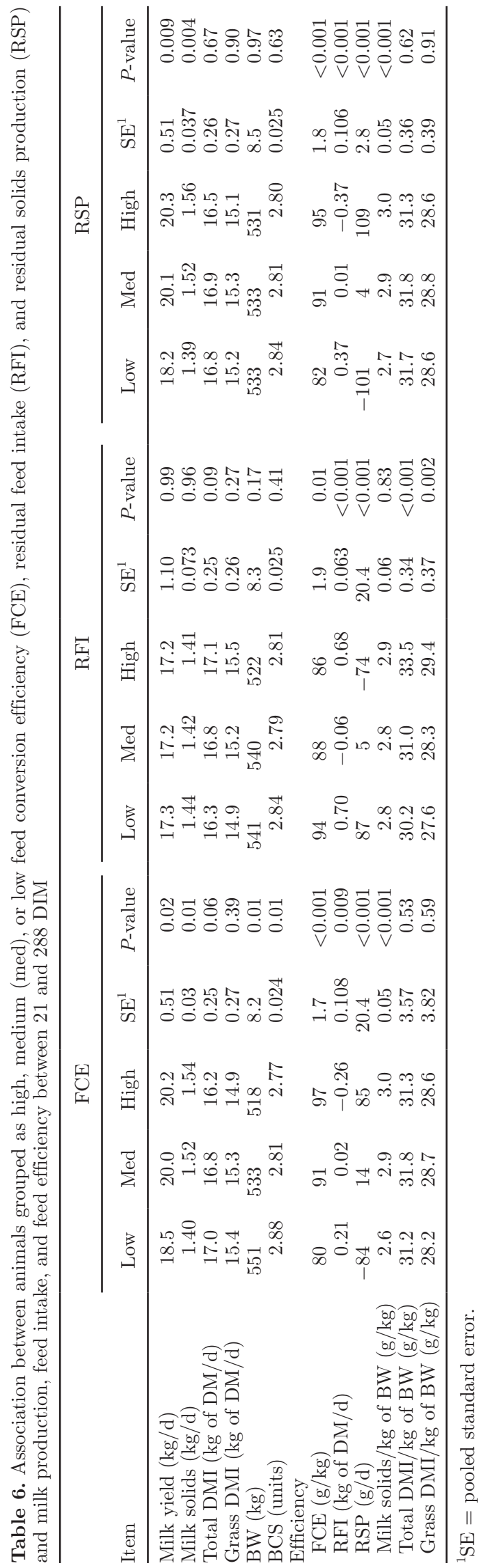

Journal of Dairy Science Vol. 93 No. 9, 2010 
क Table 7. Association between feed conversion efficiency (FCE), residual feed intake (RFI), and residual solids production (RSP) from 21 to 60 DIM on odds and hazard ratios for fertility performance variables ( $95 \% \mathrm{CI}$ in parentheses)

\begin{tabular}{|c|c|c|c|c|c|c|c|c|c|}
\hline \multirow[b]{2}{*}{ Item } & \multicolumn{3}{|c|}{$\mathrm{FCE}$} & \multicolumn{3}{|c|}{ RFI } & \multicolumn{3}{|c|}{ RSP } \\
\hline & Medium & High & $P$-value & Medium & High & $P$-value & Medium & High & $P$-value \\
\hline 24-d submission rate ${ }^{1}$ & $0.51(0.20,1.32)$ & $0.62(0.24,1.63)$ & 0.37 & $1.00(0.39,2.57)$ & $0.73(0.30,1.79)$ & 0.72 & $0.90(0.37,2.20)$ & $1.26(0.49,3.27)$ & 0.77 \\
\hline Pregnancy rate to first service ${ }^{1}$ & $1.42(0.72,2.78)$ & $1.34(0.68,2.63)$ & 0.54 & $0.84(0.43,1.63)$ & $0.89(0.45,1.73)$ & 0.87 & $1.91(0.97,3.78)$ & $2.03(1.02,4.00)$ & 0.07 \\
\hline 42-d pregnancy rate ${ }^{1}$ & $1.33(0.69,2.57)$ & $1.77(0.91,3.46)$ & 0.24 & $0.63(0.31,1.22)$ & $0.63(0.31,1.22)$ & 0.29 & $1.57(0.81,3.05)$ & $2.52(0.16,1.64)$ & 0.025 \\
\hline Embryo mortality $^{1}$ & $1.00(0.35,2.83)$ & $0.60(0.18,1.92)$ & 0.62 & $1.91(0.60,6.03)$ & $1.21(0.35,4.19)$ & 0.48 & $0.87(0.61,2.41)$ & $0.52(0.16,1.64)$ & 0.50 \\
\hline Overall pregnancy rate ${ }^{1}$ & $1.44(0.68,3.07)$ & $2.29(1.00,5.20)$ & 0.13 & $0.58(0.25,1.36)$ & $0.58(0.25,1.36)$ & 0.36 & $2.67(1.21,5.88)$ & $3.74(1.59,8.77)$ & 0.003 \\
\hline Survival $^{2}$ & $0.55(0.31,0.96)$ & $0.41(0.66,2.60)$ & 0.01 & $1.46(0.81,2.65)$ & $0.93(0.86,2.83)$ & 0.25 & $0.53(0.29,0.96)$ & $0.48(0.55,2.18)$ & 0.028 \\
\hline
\end{tabular}

${ }^{1}$ Expressed as odds ratios and $95 \%$ CI; low FCE, RFI, and RSP used as reference categories.

${ }^{2}$ Expressed as hazard ratios and 95\% CI; low FCE, RFI, and RSP used as reference categories.

Table 8. Association between feed conversion efficiency (FCE), residual feed intake (RFI), and residual solids production (RSP) from 21 to 288 DIM on odds and hazard ratios for fertility performance variables ( $95 \%$ CI in parentheses)

\begin{tabular}{|c|c|c|c|c|c|c|c|c|c|}
\hline \multirow[b]{2}{*}{ Item } & \multicolumn{3}{|c|}{ FCE } & \multicolumn{3}{|c|}{ RFI } & \multicolumn{3}{|c|}{ RSP } \\
\hline & Medium & High & $P$-value & Medium & High & $P$-value & Medium & High & $P$-value \\
\hline 24-d submission rate ${ }^{1}$ & $1.00(0.37,2.69)$ & $0.54(0.21,1.33)$ & 0.27 & $0.67(0.27,1.62)$ & $0.80(0.32,2.00)$ & 0.65 & $0.89(0.35,2.26)$ & $0.80(0.32,2.00)$ & 0.89 \\
\hline Pregnancy rate to first service ${ }^{1}$ & $1.05(0.54,2.04)$ & $0.66(0.33,1.30)$ & 0.33 & $0.74(0.38,1.46)$ & $1.11(0.57,2.16)$ & 0.47 & $1.18(0.61,2.31)$ & $1.05(0.54,2.06)$ & 0.87 \\
\hline $42-\mathrm{d}$ pregnancy rate ${ }^{1}$ & $1.61(0.81,3.17)$ & $0.84(0.44,1.63)$ & 0.15 & $0.56(0.29,1.09)$ & $0.88(0.45,1.74)$ & 0.20 & $1.05(0.54,2.04)$ & $1.41(0.72,2.76)$ & 0.55 \\
\hline Embryo mortality $^{1}$ & $1.55(0.42,5.73)$ & $2.12(0.61,7.41)$ & 0.48 & $1.00(0.33,3.01)$ & $0.54(0.15,1.95)$ & 0.57 & $1.18(0.37,3.71)$ & $1.18(0.37,3.71)$ & 0.94 \\
\hline Overall pregnancy rate ${ }^{1}$ & $1.43(0.62,3.29)$ & $1.08(0.49,2.41)$ & 0.68 & $0.57(0.26,1.26)$ & $0.91(0.39,2.11)$ & 0.30 & $1.17(0.53,2.58)$ & $1.71(0.73,3.98)$ & 0.43 \\
\hline Survival $^{2}$ & $0.71(0.38,1.30)$ & $0.88(0.42,1.53)$ & 0.54 & $1.43(0.80,2.56)$ & $0.93(0.85,2.78)$ & 0.28 & $1.26(0.70,2.25)$ & $0.79(0.85,2.94)$ & 0.33 \\
\hline
\end{tabular}

${ }^{1}$ Expressed as odds ratios and $95 \% \mathrm{CI}$; low FCE, RFI, and RSP used as reference categories.

${ }^{2}$ Expressed as hazard ratios and $95 \%$ CI; low FCE, RFI, and RSP used as reference categories. 
lactose yield, as well as metabolic BW, daily change in BW, and BCS. The inclusion of year in the model for RFI was undertaken to facilitate the separation of animals into high, medium, and low efficiency to ensure groups were created independent of year effects.

Genetic gain is a function of genetic variation; all other things equal, the greater the genetic variance, the greater the potential genetic gain. In the present study, the multiple regression model developed explained, on average, $86 \%$ of the variation in feed intake, implying that RFI represented only $14 \%$ of the variance in total DMI. In contrast, the proportion of variance in milk solids represented by RSP was, on average, $23 \%$. Milk solids yield also had a greater coefficient of variation than total DMI. This suggests that there may be greater scope for genetic gain in RSP, although genetic parameters for both traits would need to be estimated to partition the phenotypic variance into its causal components. Repeatability across lactations for both definitions of feed efficiency coupled with the existence of significant differences among genotypes suggests that both traits may be heritable, with a maximum heritability in this study of approximately 0.30 .

Although RFI is an effective method of selecting for efficiency independently of milk yield, this study highlights that it may not be the most appropriate definition of efficiency to include in breeding programs in the future. The strong correlation (0.72) between DMI and metabolic BW indicates a strong association between animal weight and DMI and, thus, the calculation of RFI. Therefore, although the HighNZ cows produced more milk solids from similar total DMI, their RFI was inferior because of their lower live weight. This does not appear correct. Milk-solids production, on the other hand, was only moderately correlated (0.44) with metabolic BW and rewarded the HighNZ animals for producing more milk solids from a similar total DMI. In addition, because RFI is independent of fat, protein, and lactose yield, the yields of animals differing in RFI is unpredictable, and thus, low RFI animals may actually be low yielding animals. The moderate correlation (0.52) between RSP and milk-solids production suggests high RSP animals, on average, produce more milk solids for a given feed intake.

Another factor unique to RFI that may confuse the end user is that lower or negative RFI is superior, unlike most other definitions of feed efficiency. The alternative to RFI described in the present study, RSP, corrects for this. Improvements in RSP are associated with increased milk-solids production while DMI, body size, and BW change remain constant. Residual solids production might be an easier method to explain to the end user because increased milk-solids production is easier to visualize and quantify than the amount of herbage consumed. To our knowledge, RSP has not been defined elsewhere, and the presence of differences in RSP among genotypes suggests that genetic variation is present and that genetic selection may be possible if incorporated into breeding programs.

Selection for RSP or RFI using traditional methods of genetic evaluation will, however, prove difficult because of the necessity of having accurate measures of traits such as feed intake, which are not routinely recorded. Although indirect selection using genetically correlated traits, such as linear type traits, may be possible, the lack of a phenotypic correlation between both RSP and RFI and BW (and milk-solids production for RSP) may result in weak correlations between linear type traits and feed efficiency. Technologies such as genomic selection (Meuwissen et al., 2001) may aid in the selection for feed efficiency if accurate phenotypes on a sufficiently large population of genotyped animals are available. More detailed studies on the genetics of feed efficiency in dairy cattle and its genetic correlation with other traits are warranted first.

\section{The Effects of Genetic Selection and Feeding Systems on DMI and Feed Efficiency}

Several studies have attempted to quantify the intake potential of dairy cows across lactation, although the majority of these studies have been conducted within confinement systems (Roseler et al., 1997; de Vries et al., 1999). Detailed studies of grazing dairy cow systems incorporating intake measurements throughout lactation are sparse because of the practicalities of measuring DMI at pasture. Mackle et al. (1996) examined the differences in DMI and FCE of Jersey and Holstein heifers across lactation, although daily herbage allowances were excessively high and not representative of intensive management systems. Other studies (Kennedy et al., 2003; McCarthy et al., 2007) have attempted to quantify the intake requirements of animals of various genotypes and feed systems at different stages of the grazing season, but this is the first study to fully quantify the lactation profile for DMI across lactation in intensive pasture-based systems of milk production.

Kennedy et al. (2003) reported that animals with greater milk yield potential consumed more to fulfill their genetic potential, and McCarthy et al. (2007) documented that smaller animals of New Zealand HF origin consumed less than larger animals of North American HF origin, although in both experiments, daily herbage allowances were high and grazing intensity was less intensive. By comparison, in the current study, animals of different genotypes, managed under more intensive systems with reduced feed allowances and high levels of grass utilization, consumed similar 
total DMI regardless of body size or milk yield potential. The increase in DMI from parturition up to 120 DIM followed by a decline until the end of lactation is similar to DMI curves across lactation observed by Roseler et al. (1997) and Mackle et al. (1996), although Berry et al. (2006) reported no decrease in net energy intake after 100 DIM among HF under Irish grazing conditions.

The high levels of grass utilization (characterized by the low postgrazing height observed), coupled with the lack of a difference in total DMI between the different genotypes, suggests the intake capacity of each genotype may not be completely fulfilled due to the grazing intensity of both feed systems on this trial (Journet and Demarquilly, 1979). Within intensive pasture-based feeding systems, increasing milk-solids output per cow is limited unless the diet is supplemented using high cost external feed sources (Dillon et al., 1995). Traditionally, increased concentrate supplementation results in reduced pasture utilization (McEvoy et al., 2008), and increased stocking rates result in decreased production per cow (Journet and Demarquilly, 1979). In this study, the combination of increased stocking rates and concentrate supplementation increased overall milksolids production per hectare but also increased total DMI and milk solids per cow, as well as total DMI per kilogram of BW. When animals on each feed system were compared for RFI, animals on the HC feed system appeared to have inferior feed efficiency, although overall milk-solids production for the $\mathrm{HC}$ feed system was significantly increased. When feed systems were compared using FCE, the increased milk-solids production per kilogram of DMI was a result of the dilution of maintenance requirements observed due to increased concentrate supplementation. These results agree with the findings of Pryce et al. (2005), who observed increased efficiency at higher levels of concentrate supplementation. Similarly, animals on the HC feed system had increased RSP when compared with animals on the MK feed system, although RFI was poorer for the animals in the HC feed system.

\section{Association Between Different Definitions of Feed Efficiency and Performance}

Future pasture-based systems of milk production will be characterized by the ability of a cow to produce the majority of milk solids from grazed grass. At the farm level, the primary limiting factor of production under intensive pasture-based feed systems is the ability to grow and supply adequate nutrients to the herd throughout the year. Therefore, a method or trait for identifying animals capable of increased milk-solids production from restricted levels of intakes with no unfavorable correlated effects would be a beneficial addition to a breeding program for increasing efficiency into the future.

The associations between the definitions of feed efficiency and performance as quantified by separating the animals into 3 groups for feed efficiency are merely associations and do not imply cause and effect of selection. Therefore, either controlled experiments using animals selected on feed efficiency would need to be undertaken or genetic parameters estimated to accurately quantify the expected response to selection on the different definitions of efficiency. The results in the present study can be used, however, as an indication of the likely response to selection. The lack of an association between RFI and fertility but the existence of an association between RSP and fertility suggest that selection for improved RSP may lead to greater responses in economic performance as well as, on average, cows that yield more milk solids. The reasons for such a difference are not clear but are nonetheless possible because RFI and RSP are not the same trait, as evidenced by the lack of a unity correlation between them. Controlled studies comparing animals selected on both definitions would need to be undertaken to confirm or refute the associations observed in the present study and to elucidate the biological pathways underpinning these differences, if they truly exist.

\section{CONCLUSIONS}

This is the first study to describe a comprehensive lactation profile for DMI in intensive pasture-based systems of milk production. When managed intensively, genetic improvement and genetic origin had no effect on DMI across lactation. This study shows that increased stocking rates, when combined with increased concentrate supplementation, increased milk-solids production per cow through increased total DMI while maintaining high levels of pasture utilization. Further analysis of feed efficiency within this study showed that although there are differences in efficiency between different genotypes of $\mathrm{HF}$, there are also significant differences within genotype or feed system. Analysis of definitions of feed efficiency within this study showed that although selection for feed efficiency is important, the associations between definitions of feed efficiency and performance were different. Residual solids production is an alternative definition of feed efficiency that identifies increased milk-solids production for a given feed intake. This study also showed that animals exhibiting increased RSP had improved fertility performance.

\section{ACKNOWLEDGMENTS}

This project was partly financially supported by the Research Stimulus Fund (Department of Agriculture, 
Food and Forestry, Dublin, Ireland; RSF-06-353).The authors acknowledge the support of Chris Grainger (formerly of Department of Primary Industries, Victoria, Australia) for his helpful comments and suggestions during the preparation of this manuscript. We thank the staff of Curtins Farm, Moorepark, Ireland, for their cooperation, care, and management of the experimental cows.

\section{REFERENCES}

Archer, J. A., P. F. Arthur, R. M. Herd, P. F. Parnell, and W. S. Pitchford. 1997. Optimum postweaning test for measurement of growth rate, feed intake and feed efficiency of British bred cattle. J. Anim. Sci. 75:2024-2032.

Berry, D. P. 2009. Improving feed efficiency in cattle with residual feed intake. Pages 67-99 in Recent Advances in Animal Nutrition 2008. P. C. Garnsworthy and J. Wiseman, eds. Nottingham Univ. Press, Nottingham, UK.

Berry, D. P., J. M. Lee, K. A. MacDonald, and J. R. Roche. 2007a. Body condition score and body weight effects on dystocia and stillbirths and consequent effects on postcalving performance. J. Dairy Sci. 90:4201-4211.

Berry, D. P., L. Shalloo, A. R. Cromie, R. F. Veerkamp, P. Dillon, P. R. Am, J. F. Kearney, R. D. Evans, and B. Wickham. 2007b. The economic breeding index: A generation on. Technical report to the Irish Cattle Breeding Federation.

Berry, D. P., R. F. Veerkamp, and P. Dillon. 2006. Phenotypic profiles for body weight, body condition score, energy intake and energy balance across different parities and concentrate feeding levels. Livest. Sci. 104:1-12.

Brody, S. 1945. Bioenergetics and Growth. Rheinhold Publishing Corp., New York, NY.

Buckley, F., B. Horan, N. Lopez-Villalobos, and P. Dillon. 2007. Milk production efficiency of varying dairy cow genotypes under grazing conditions. Pages $74-83$ in Meeting the Challenges for Pasture-Based Dairying. Proc. 3rd Dairy Sci. Symp., University of Melbourne, Victoria, Australia.

Coleman, J., K. M. Pierce, D. P. Berry, A. Brennan, and B. Horan. 2009. The influence of genetic selection and feed system on the reproductive performance of spring-calving dairy cows within future pasture-based production systems. J. Dairy Sci. 92:52585269.

Coleman, J., K. M. Pierce, D. P. Berry, A. Brennan, and B. Horan. 2010. Increasing milk solids production across lactation through genetic selection and intensive pasture-based feed system. J. Dairy Sci. 93:4302-4317.

de Vries, M. J., S. Van Der Beek, L. M. T. E. Kaal-Lansbergen, W. Ouweltjes, and J. B. M. Wilmink. 1999. Modeling of energy balance in early lactation and the effect of energy deficits in early lactation on first detected estrus postpartum in dairy cows. J. Dairy Sci. 82:1927-1934.

DiCostanzo, A., J. C. Meiske, S. D. Plegge, T. M. Peters, and R. D. Goodrich. 1990. Within-herd variation in energy utilization of maintenance and gain in beef cows. J. Anim. Sci. 68:2156-2165.

Dillon, P., S. Crosse, G. Stakelum, and F. Flynn. 1995. The effect of calving date and stocking rate on the performance of spring calving dairy cows. Grass Forage Sci. 50:286-299.

Dillon, P., T. Hennessy, L. Shalloo, F. Thorne, and B. Horan. 2008. Future outlook for the Irish dairy industry: A study of international competitiveness, influence of international trade reform and requirement for change. Int. J. Dairy Technol. 61:16-29.

Dillon, P., and G. Stakelum. 1989. Herbage and dosed alkanes as a grass measurement technique for dairy cows. Isr. J. Agric. Res. 28:104. (Abstr.)

Edmonson, A. J., I. J. Lean, L. D. Weaver, T. Farver, and G. Webster. 1989. A body condition scoring chart for Holstein dairy cows. J. Dairy Sci. 72:68-78.
Gilmour, A. R., B. R. Cullis, S. J. Welham, and R. Thompson. 2009. ASREML Reference Manual. New South Wales Agriculture, Orange Agricultural Institute, Orange, NSW, Australia.

ICBF (Irish Cattle Breeding Federation). 2008. Irish Cattle Breeding Statistics 2008. Irish Cattle Breeding Society Limited, Shinagh House, Bandon, Co. Cork, Ireland.

Journet, M., and C. Demarquilly. 1979. Grazing. Pages 295-321 in Feeding Strategy for the High Yielding Cow. W. H. Broster and H. Swan, eds. Granada, London, UK.

Kennedy, J., P. Dillon, P. Faverdin, L. Delaby, G. Stakelum, and M. Rath. 2003. Effect of genetic merit and concentrate supplementation on grass intake and milk production with Holstein-Friesian dairy cows. J. Dairy Sci. 86:610-621.

Koch, R. M., L. A. Swiger, D. Chambers, and K. E. Gregory. 1963. Efficiency of feed use in beef cattle. J. Anim. Sci. 22:486-494.

Lopez-Villalobos, N., D. P. Berry, B. Horan, F. Buckley, J. Kennedy, M. O'Donovan, L. Shalloo, and P. Dillon. 2008. Genetics of residual feed intake in Irish grazing dairy cows. Proc. N. Z. Soc. Anim. Prod. 68:97-100.

Mackle, T. R., C. R. Parr, G. K. Stakelum, A. M. Bryant, and K. L. MacMillan. 1996. Feed conversion efficiency, daily pasture intake and milk production of primiparous Friesian and Jersey cows calved at two different liveweights. N. Z. J. Agric. Res. 39:357-370.

Mayes, R. W., C. S. Lamb, and P. A. Colgrove. 1986. The use of dosed n-alkanes as markers for the determination of herbage intake. J. Agric. Sci. 107:161-170.

McCarthy, S., B. Horan, M. Rath, M. Linnane, P. O'Connor, and P. Dillon. 2007. The influence of strain of Holstein-Friesian dairy cow and pasture-based feeding system on grazing behaviour, intake and milk production. Grass Forage Sci. 62:13-26.

McEvoy, M., E. Kennedy, J. P. Murphy, T. M. Boland, L. Delaby, and M. O'Donovan. 2008. The effect of herbage allowance and concentrate supplementation on milk production performance and dry matter intake of spring-calving dairy cows in early lactation. J. Dairy Sci. 91:1258-1269.

Meuwissen, T. H. E., B. J. Hayes, and M. E. Goddard. 2001. Prediction of total genetic value using genome-wide dense marker maps. Genetics 157:1819-1829.

National Research Council. 2001. Nutrient Requirements of Dairy Cattle. 7th rev. ed. Natl. Acad. Sci., Washington, DC.

O'Donovan, M. 1997. Improved techniques for grazing management. M.AgrSc Thesis. National University of Ireland, Dublin.

O'Donovan, M. 2000. The relationship between the performance of dairy cows and grassland management practice on intensive dairy farms in Ireland. PhD Thesis. National University of Ireland, Dublin.

O'Mara, F. 2000. A net energy system for cattle and sheep. Version 1.2. Univ. Coll. Dublin, Ireland.

Pryce, J. E., B. L. Harris, W. A. Montgomerie, R. Jackson, K. A. MacDonald, C. B. Glassey, B. S. Thorrold, and C. W. Holmes. 2005. Comparing feed allowances to inferred energy intake using data from a dairy grazing farm trial. Proc. N. Z. Soc. Anim. Prod. $65: 225-230$.

Roche, J. R., K. A. Macdonald, C. R. Burke, J. M. Lee, and D. P. Berry. 2007. Associations among body condition score, body weight and reproductive performance in seasonal-calving dairy cattle. J. Dairy Sci. 90:376-391.

Roseler, D. K., D. G. Fox, L. E. Chase, A. N. Pell, and W. C. Stone. 1997. Development and evaluation of equations for prediction of feed intake for lactating Holstein dairy cows. J. Dairy Sci. 80:878-893.

Shalloo, L., J. Kennedy, M. Wallace, M. Rath, and P. Dillon. 2004. The economic impact of cow genetic potential for milk production and concentrate supplementation level on the profitability of pasture based systems under different EU milk quota scenarios. J. Agric. Sci. 142:357-369.

SAS Institute. 2006. Users Guide: Statistics. Version 9.1. SAS Inst. Inc., Cary, NC.

Wilmink, J. B. M. 1987. Adjustment of lactation yield for age at calving in relation to level of production. Livest. Prod. Sci. 16:321-334. 